\title{
Laser Surface Remelting and Hardening of an Automotive Shaft Sing a High-power Fiber Laser
}

\author{
Milton Sergio Fernandes de Lima*, Flávia Aline Goia ${ }^{\mathrm{a}}$, Rudimar Riva ${ }^{\mathrm{a}}$, Ana Maria do Espírito Santo \\ anstitute for Advanced Studies IEAv, \\ Rodovia dos Tamoios, Km 5.5, 12228-001 São José dos Campos - SP, Brazil \\ ${ }^{\mathrm{b}}$ Universidade do Vale do Paraíba - UNIVAP, Institute of Research and Development - IP\&D, \\ 12244-000 São José dos Campos - SP, Brazil
}

Received: August 10, 2007; Revised: September 20, 2007

\begin{abstract}
An automotive shaft was surface-remelted and hardened using a $2 \mathrm{~kW}$ fiber laser and an adapted linear axis whose rotating axis produced helical tracks at 120 RPM. The process variable was the laser power, ranging from 300 to $1100 \mathrm{~W}$, which produced two regions in the material: a martensitic region (MR) and a partially transformed region (PTR). The MR is formed after rapid solidification or austenitization followed by rapid cooling $\left(10^{7} \mathrm{~K} \cdot \mathrm{s}^{-1}\right)$. The PTR is composed of martensite, unchanged pearlite and proeutectoid ferrite. The maximum case depth was about $0.3 \mathrm{~mm}$. The microhardness inside the martensitic regions are at least double that of the base material, i.e. between 800 than $600 \mathrm{HV}$ compared to $300 \mathrm{HV}$. Thermal simulations using a modified Rosenthal formalism help elucidate the phase transformation inside the material and show good agreement with experimental results. The experimental laser-steel absorptivities were measured; they ranged between 38 and 59\% depending on the laser power and the amount of liquid at the surface.
\end{abstract}

Keywords: laser surface hardening, laser remelting, fiber laser

\section{Introduction}

Laser surface hardening is a method of producing martensite on selected regions of steel components. A continuous wavelength laser is scanned over the item to heat the surface up to the austenite range (approximately $1000{ }^{\circ} \mathrm{C}$ in most steels). Since the substrate acts as an efficient heat sink, the material quickly cools to a temperature below Ms (martensite start temperature). The resulting microstructure is composed of fine martensite, which improves mechanical and chemical surface properties, but maintains unchanged material bulk properties, including ductility and toughness.

Because of wide availability, both $\mathrm{CO}_{2}$ and $\mathrm{Nd}$ :YAG lasers have been used to produce hardened surfaces on steels ${ }^{1-3}$. When using $\mathrm{CO}_{2}$ lasers, surface coatings are usually needed in order to increase the laser-matter surface absorptivity. One popular method to achieve this is by spraying the surface with colloidal graphite, which can be easily removed after the treatment. Chiang and $\mathrm{Chen}^{4}$ studied the laser surface hardening of $\mathrm{H} 13$ steel using a $2 \mathrm{~kW} \mathrm{CO} 2$ laser. For pieces previously coated with $\mathrm{Mn}\left(\mathrm{H}_{2} \mathrm{PO}_{4}\right)$, these authors obtained a maximum hardened depth of $420 \mu \mathrm{m}$ using a beam power of $250 \mathrm{~W}$ and speed of $10 \mathrm{~mm} \cdot \mathrm{s}^{-1}$. Under these conditions, they found two well-defined regions, a partially transformed region and a resolidified martensitic region. Similar studies using a $\mathrm{CO}_{2}$ laser had been carried out by Selvan et al. ${ }^{5}$. In that study of AISI 5135 steel, the laser process had increased the hardness of the base metal from 250 to $900 \mathrm{HV}$. This 3-fold increase in hardness was obtained with a maximum case depth of 0.45 and $0.65 \mathrm{~mm}$ at respective laser powers of 1.3 and $1.5 \mathrm{~kW}$. Prior to laser treatment, the specimen surface was roughened with 220 grit paper, and then coated with $\mathrm{MoS}_{2}$ to increase the energy absorption.

Solid-state lasers with shorter wavelengths produce better laser-matter coupling, and so an absorptive coating might not be necessary. Lo et al. ${ }^{6}$ used a Nd:YAG laser to surface treat an AISI 440C martensitic stainless steel. The case depth was about $100 \mu \mathrm{m}$ for a microhardness between 600 and $800 \mathrm{HV}$ (the base material was $300 \mathrm{HV})$. These authors were particularly concerned with the cavitation erosion improvement after laser treatment, which was approximately three-fold higher than that achieved by conventional heat treatments. Obergfell et al. ${ }^{7}$ studied the hardenability of three different steels using a Nd:YAG laser and an experimental set-up similar to the Jominy test. These authors associate the hardening effect in proeutectoid steels with two mechanisms: i) increase in carbon content dissolved in the austenite matrix with subsequent martensite and dislocation formations and ii) strengthening due to fine carbide dispersions (tempering).

High-power diode lasers are very popular for surface hardening due to the high absorptivity of metals and the typical rectangular beam shape, approximately a top hat in both directions, which allows large areas to be treated. Kennedy et al. ${ }^{8}$ reviewed the literature on the use of high-power diode lasers for surface hardening. Diode laser packs are economical and compact solutions when the beam quality is not a major concern, particularly for integration into conventional machine systems and robotics.

Nowadays, high-power fiber lasers are a new heat source available for materials processing. Unlike conventional lasers, fiber lasers are virtually maintenance-free and present very good electrical efficiency and exceptional beam quality. Fiber lasers are quickly decreasing the ratio of light power per initial investment $\left(\mathrm{W} . \$^{-1}\right)$, so they have been considered a new paradigm for various industrial needs, in particular for replacement of Nd:YAG lasers. As long as fiber lasers are available on the work floor, more and more applications such as surface treatments will appear. Heretofore, very few data are available about fiber laser surface hardening; this paper intends to contribute to this area.

The current technological problem to be solved is how to propose an alternative route for surface hardening of a specific automotive shaft that has usually been induction-hardened. The laser technology is considered a good candidate because the variety of part shapes to be 
hardened could pose problems for the induction coil manufacturing and for induction coupling, and also because one wants to choose specific treatment regions.

The objective of the present work is to characterize the surfacehardened layer of an AISI 1040 steel shaft produced by a high-power fiber laser at different power levels. The experimental dimensions of the hardening tracks will be compared to the simulated results.

\section{Materials and Methodology}

An AISI 1040 steel automotive shaft of $14 \mathrm{~cm}$ length and maximum diameter of $1.8 \mathrm{~cm}$ was used for the laser treatment. Although the shaft diameter changes along the axis, only portions with same diameter were treated. Proeutectoid ferrite and pearlite comprise the original microstructure. The surface condition was as-machined, with waviness of about $400 \mu \mathrm{m}$ wide and $15 \mu \mathrm{m}$ depth, degreased and cleaned with ethanol. The shaft was fixed to a rotating axis attached to a translation table as presented schematically in Figure 1. The shaft was fixed to a motor-driven spindle on one side and to a centralizing fixture on the other side. An external driver controlled the spinning velocity and a CNC linear axis table assured the horizontal motion. All speeds and alignments of parts were previously calibrated using a machined rod in place of the shaft.

The $2 \mathrm{~kW} \mathrm{CW}$ fiber laser (IPG photonics) used was with a $10 \mathrm{~m}$ long optical cable and a focusing head. The focusing head was composed of a collimator, which produces a parallel beam from the fiber output; transmissive focusing optics; and a gas delivery cone. The lens focusing distance was $160 \mathrm{~mm}$ but the working distance was set at $170 \mathrm{~mm}$, so the laser beam was defocalised relative to the surface. The beam shape was approximately Gaussian, with beam quality $\mathrm{M}^{2}=17$. The beam diameter over the piece was $1.9 \mathrm{~mm}$ as measured using a CCD infrared sensor. The gas nozzle was placed very close to the shaft surface and $\mathrm{N}_{2}(15 \mathrm{l} / \mathrm{min})$ was utilized as the cooling gas. Figure 1 presents a schematic representation of the experimental set-up.

The rotating speed was set at 120 RPM, the equivalent of a $115 \mathrm{~mm} \cdot \mathrm{s}^{-1}$ surface speed. Using a horizontal speed of $2 \mathrm{~mm} \cdot \mathrm{s}^{-1}$, the distance between the laser tracks' centers at the surface was $1 \mathrm{~mm}$. Five levels of laser power were used to produce the tracks: 300, 500, 700,900 and $1100 \mathrm{~W}$. The laser power was shifted every 5 seconds to produce segments of $10 \mathrm{~mm}$ for each power level.

Microstructural analyses were carried out by electron and optical microscopy and by microhardness testing on a longitudinal (along the axis) cross cut. Samples were extracted using a carbide saw, polished with diamond powder and etched with Nital $2 \%$ solution. The experimental dimensions of the laser tracks were measured by optical microscopy six times for each laser condition; their standard deviations are 5 and $8 \%$ for the depth and width, respectively. A

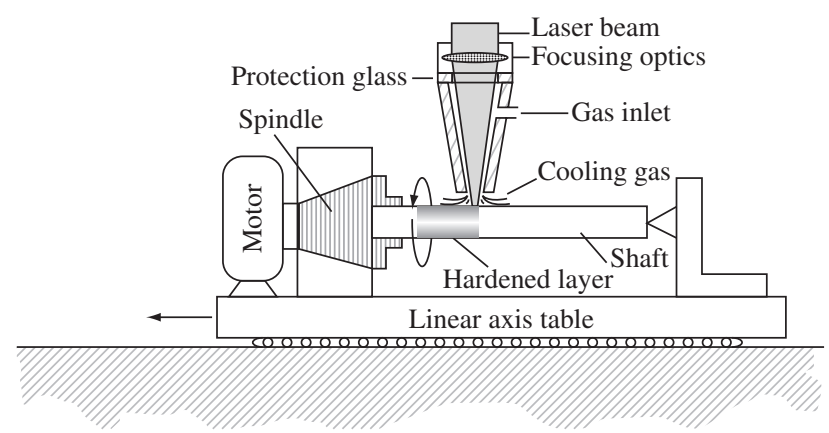

Figure 1. Experimental setup schematics for the shaft laser surface hardening.
JSM6340F field emission gun scanning electron microscope (FEGSEM) with accelerating voltage of $5 \mathrm{keV}$ was also used for microstructural analyses.

Microhardness testing (Vickers hardness testing - HV) was accomplished using a $100 \mathrm{gf}$ load cell for 9 seconds. The measurements were carried out both from the top to the bottom of the laser tracks and laterally, with measurements taken starting at the laser beam axis and $50 \mu \mathrm{m}$ from the upper surface. Scattering of the HV values when measured in the same region inside the hardened layer was about $15 \%$.

\subsection{Thermal simulations}

The energy absorbed during laser beam heating is mainly from heat conduction dissipated to the solid volume; thus, the temperature field could be calculated from the heat diffusion equation. Hunziker ${ }^{9}$ has proposed a solution for a Gaussian heat source at constant velocity, $\mathrm{V}_{\mathrm{b}}$, over a semi-infinite solid. This solution is based on integration of the uniform source solution originally proposed by Rosenthal ${ }^{10}$, with axis origin at the intersection of the laser beam axis with the materials surface. The model assumes constant and isotropic thermal properties, conductivity and specific heat, and negligible latent heat. The steady-state temperature distribution of a Gaussian heat source is then given by:

$$
\begin{aligned}
& \mathrm{T}(\mathrm{x}, \mathrm{y}, \mathrm{z})=\mathrm{T}_{0}+\frac{\beta \mathrm{P}}{\sqrt{2 \pi^{3}} \kappa} \times \frac{1}{\sigma} \int_{0}^{\infty} \frac{\exp (-\mathrm{H})}{1+\xi^{2}} \mathrm{~d} \xi \\
& \mathrm{H}=\frac{\left(\mathrm{x} / \sigma^{+}+\xi^{2} \mathrm{P}_{\mathrm{t}}\right)^{2}+(\mathrm{y} / \sigma)^{2}}{2\left(1+\xi^{2}\right)}+\frac{(\mathrm{z} / \sigma)^{2}}{2 \xi^{2}}
\end{aligned}
$$

where $\mathrm{T}_{0}$ is the ambient temperature; $\beta$ is the laser-matter absorptivity; $\mathrm{P}$ is the laser power; $\mathrm{k}$ is the thermal conductivity; $\sigma$ is the variance of the Gaussian; $\xi$ is the integration variable calculated as $(\alpha . t)^{1 / 2}$, with $\alpha$ as the thermal diffusivity and $t$ as the elapsed time; $P_{t}$ is the Péclet number for thermal diffusion defined as $\mathrm{P}_{t}=\sigma \cdot \mathrm{V}_{\mathrm{b}} /(2 \alpha)$. For the present case, the material constants in Equation $1 \mathrm{are}^{11}: \kappa=51.9 \mathrm{~W} \cdot \mathrm{m}^{-1} \cdot \mathrm{K}^{-1}$ and $\alpha=1.36 \times 10^{-5} \mathrm{~m}^{2} \mathrm{~s}^{-1}$.

For these simulations, Ac1 and Ac3 are used as the two reference temperatures which represent the boundaries for $100 \%$ pearlitic and $100 \%$ austenitic regions in the phase diagram for this particular steel. The Ac1 temperature was estimated as $993 \mathrm{~K}$ as given by the phase diagram $^{12}$. The Ac3 temperature, on the other hand, was considered to be $1145 \mathrm{~K}$, a value attained by adding $100 \mathrm{~K}$ overheating to the phase diagram temperature in order to take phase transformation kinetics into account ${ }^{13}$. The assumption here is that the transformation of pearlite into austenite begins just above the equilibrium temperature Ac1. However, due to the rapid raise in temperature, the diffusion process between austenite and ferrite requires further thermodynamic potential (overheating). The isotherms of 993 and $1145 \mathrm{~K}$ were fixed in the left-hand side of Equation 1 and then the limits of the partially transformed region (PTR) and martensitic region (MR) could be estimated.

The absorptivity of the laser beam on steel $(\beta)$ is an unknown variable which could be estimated from calorimetric tests ${ }^{14}$. A small piece of the steel was subjected to a laser pulse of average power $(\mathrm{P})$ during a given period $\left(\mathrm{t}_{\mathrm{p}}\right.$ ). For a system isolated from the environment, the temperature rise $(\Delta \mathrm{T})$ is linked to the amount of energy added to the system, in the form of the well-known Equation 2:

$$
\beta \cdot P \cdot t_{p}=\rho \cdot V \cdot C_{p} \cdot \Delta T
$$

where $\rho$ is the density of solid; $\mathrm{V}$ is the volume of the irradiated solid; and $C_{p}$ is the specific heat. It is now possible to measure $\beta$ for each 
experimental condition using a calorimeter by disregarding the energy lost to phase transformations (latent heat) and the heat transfer to the surroundings. This latter is reduced by using a soft tissue of alumina fiber around the coupon.

In the present work, the steel coupon was $7.02 \mathrm{~g}$ and the laser pulse was $0.13 \mathrm{~s}$ long $\left(\mathrm{t}_{\mathrm{p}}\right)$. The physical constants were obtained from the literature $^{11}$. The coupon temperature was recorded using a thermocouple and computer recording software. The steel coupon was at ambient temperature $\left(21^{\circ} \mathrm{C}\right)$ at the beginning of each run. The maximum temperature was obtained by extrapolating the cooling curve to $t=0$ (laser pulse start). Further information about the experimental set-up for laser calorimetry can be obtained in refs. 14 and 15 .

\section{Results}

\subsection{Microstructure}

Figure 2 shows the observed microstructures of the steel laser tracks for different laser power levels. With the exception of Figure $2 \mathrm{a}$, all micrographs present two well-defined regions: i) a bright region near the top-center of the track and ii) a region marked by gray veins.

Figure 2a shows some gray veins of the unsolved proeutectoid ferrite inside the white mark obtained when using 300-W beam power. In Figure $2 b(500 \mathrm{~W})$, the austenitized region (bright) appears although ferrite veins extend over almost the entire bead. The austenitized region transforms to martensite during rapid cooling. When using 700, 900 or $1100 \mathrm{~W}$ laser powers (Figures $2 \mathrm{c}, \mathrm{d}, \mathrm{e}$ ), two different treated regions are evident: i) the Martensite Region (MR), a bright white region at top-center composed of martensite; and ii) the Partially-Transformed Region (PTR) composed of proeutectoid ferrite, untransformed pearlite and martensite. These regions can be better seen with scanning electron microscopy, as in Figure 3. Figure $3 \mathrm{a}$ is a low magnification picture of the regions in a $700 \mathrm{~W}$ hardened bead. Figure $3 \mathrm{~b}$ shows the interface between the base material and the PTR marked by the pearlite colonies below and martensite grains above (gray phase). The martensite morphology and dimensions are approximately the same in the PTR or MR for this range of laser power. Figure $3 \mathrm{c}$ shows needle-like martensite inside the $1100 \mathrm{~W}$ processed sample.

When using a laser power of 900 or $1100 \mathrm{~W}$, the laser tracks are larger than $1 \mathrm{~mm}$ and further phase transformations occur at the intersection between consecutive laser tracks. These overlapped regions presents a very fine carbide dispersion because of martensite decomposition (tempering) and further carbon diffusion from the residual austenite. Figure $3 \mathrm{~d}$ presents a micrograph of two overlapping tracks in the $900 \mathrm{~W}$ treated steel. Inside the superposition region (arrow in Figure 3d), carbides are visible around a martensitic matrix (Figure 3e)

The average measured dimensions of maximum depth (d) and width at surface $(w)$ of the PTR and MR regions are presented in Table 1 . Note that the partially transformed region contains the martensitic region.

\subsection{Absorptivity and temperature profile}

The results of the measured maximum temperature $\left(\mathrm{T}_{\max }\right)$ and the absorptivities for each laser power are presented in Table 2 .

Now, Equation 1 enables estimation of the temperature profile for each power level. Figure 4 shows these temperatures as a function of distance from the laser beam center $(\mathrm{x}=0)$. The temperatures were estimated in a point at the beam centerline and $50 \mu \mathrm{m}$ below the surface. The pearlite-to-austenite start and finish temperatures are signed Ac1 and Ac3, respectively. Laser beam motion $\left(\mathrm{Vb}=115 \mathrm{~mm} \cdot \mathrm{s}^{-1}\right)$ is to the right; negative values represent positions behind the laser beam.

A comparison between the simulated and experimental results is shown in Figure 5. Figure 5a compares the measured depth and width of the partially transformed region (PTR) with the simulation

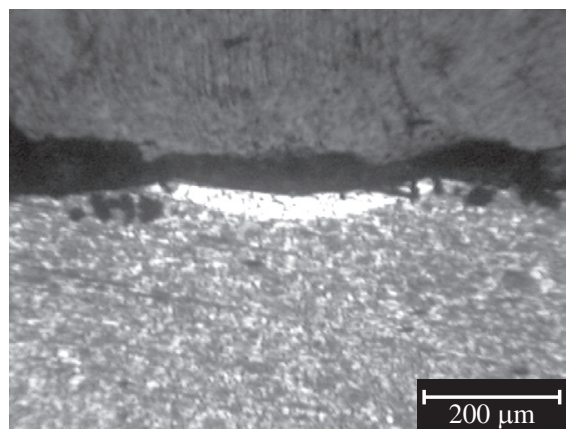

(a)

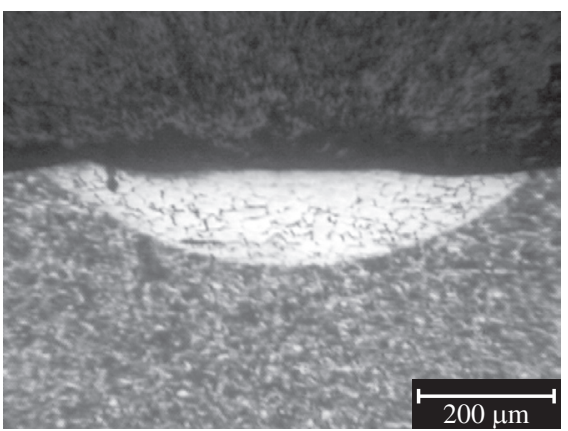

(b)

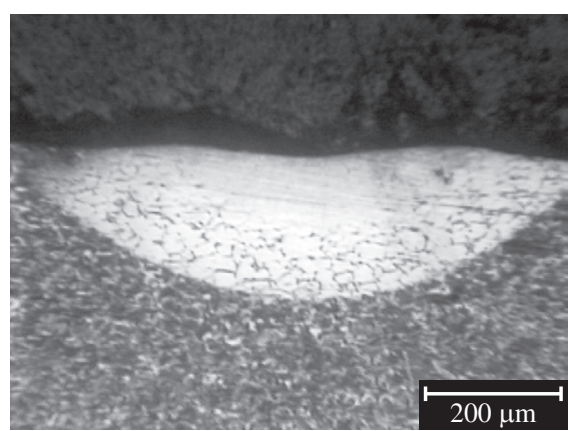

(c)

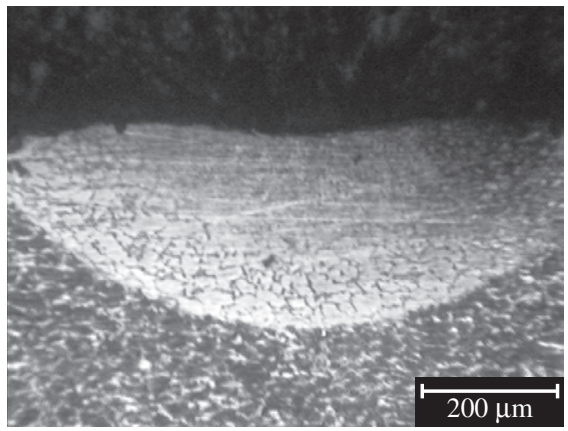

(d)

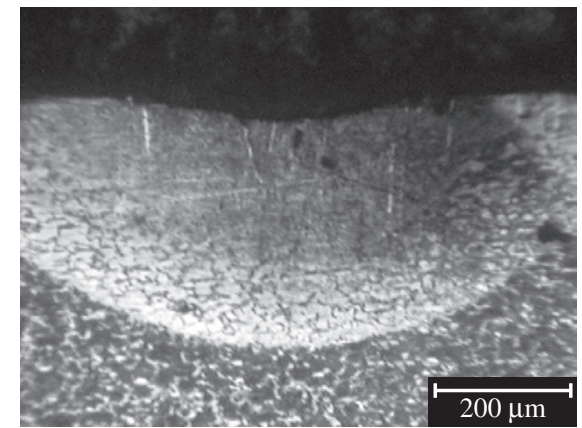

(e)

Figure 2. Micrographs of laser heat tracks inside the steel (transversal cuts) for different power levels: a) $300 \mathrm{~W}$; b) $500 \mathrm{~W}$; c) $700 \mathrm{~W}$; d) $900 \mathrm{~W}$; and e) $1100 \mathrm{~W}$. 


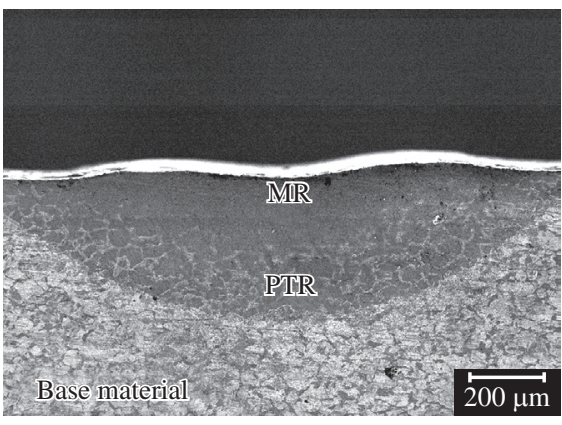

(a)

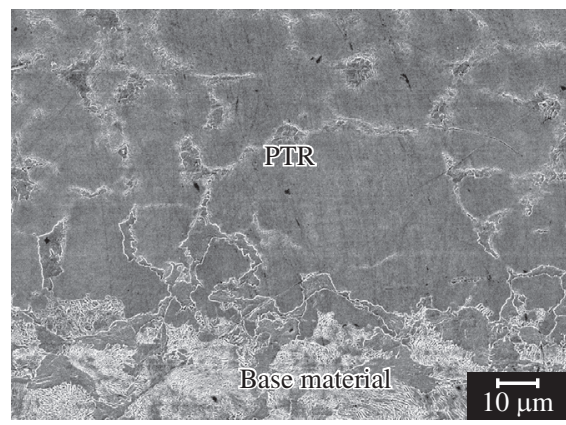

(b)

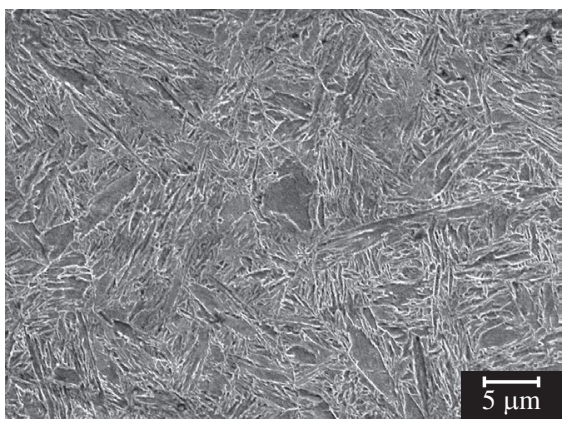

(c)

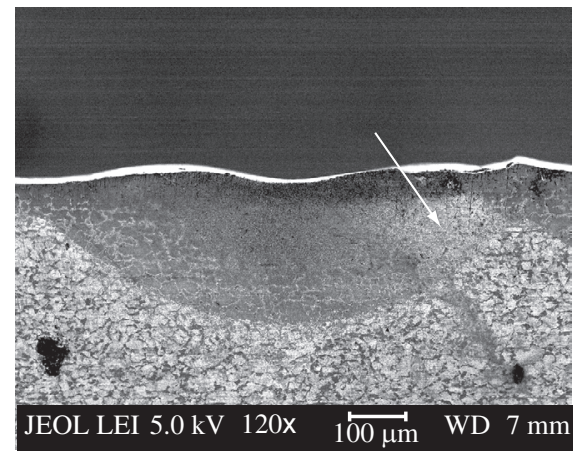

(d)

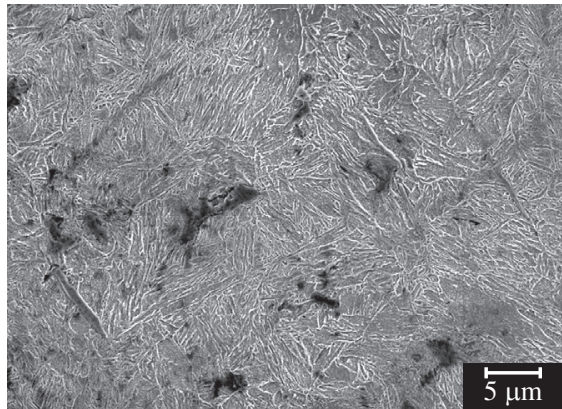

(e)

Figure 3. Scanning electron microscope images: a) General aspect of the hardened zone (700 W); b) interface between base material and PTR (700 W); c) martensite laths inside the hardened region $(1100 \mathrm{~W})$; d) partially superposed tracks at $900 \mathrm{~W}$ with arrow identifying the tempered region; and e) tempered martensite inside the overlapped region (zoomed-in view of the region indicated by an arrow in Figure $3 \mathrm{~d}$ ).

Table 1. Measurements of average depth (d) and width (w) of the transformed interface in the laser tracks for the partially transformed and the martensitic regions.

\begin{tabular}{rccccc}
\hline Power $(\mathrm{W})$ & \multicolumn{2}{c}{ Partially transformed region } & & \multicolumn{2}{c}{ Martensitic region } \\
\cline { 2 - 3 } \cline { 5 - 6 } & $\mathrm{d}_{\mathrm{PTR}}(\mu \mathrm{m})$ & $\mathrm{w}_{\text {PTR }}(\mu \mathrm{m})$ & & $\mathrm{d}_{\mathrm{M}}(\mu \mathrm{m})$ & $\mathrm{w}_{\mathrm{M}}(\mu \mathrm{m})$ \\
\hline 300 & 43 & 451 & - & - \\
500 & 151 & 807 & 36 & 222 \\
700 & 209 & 899 & 112 & 432 \\
900 & 233 & 968 & 163 & 605 \\
1100 & 369 & 1325 & 225 & 851 \\
\hline
\end{tabular}

Table 2. Experimental data from the calorimetric tests.

\begin{tabular}{ccc}
\hline Power $(\mathrm{W})$ & $\mathrm{T}_{\max }\left({ }^{\circ} \mathrm{C}\right)$ & $\beta(\%)$ \\
\hline 300 & 25.1 & 38.1 \\
500 & 29.5 & 44.3 \\
700 & 32.4 & 40.0 \\
900 & 34.1 & 40.8 \\
1100 & 41.0 & 59.4 \\
\hline
\end{tabular}

results for different laser powers. The simulation results at $300 \mathrm{~W}$ could not be obtained because the calculated temperatures are below Ac1 (Figure 4). Figure 5b presents the simulated and measured dimensions for the martensitic region (MR).

\subsection{Microhardness}

The microhardness profile for each laser condition is presented in Figure 6. Figure 6a shows the microhardness as a function of depth (case depth) starting $50 \mu \mathrm{m}$ from the surface at the laser axis. Figure $6 \mathrm{~b}$ shows the lateral microhardness profile (parallel to surface)

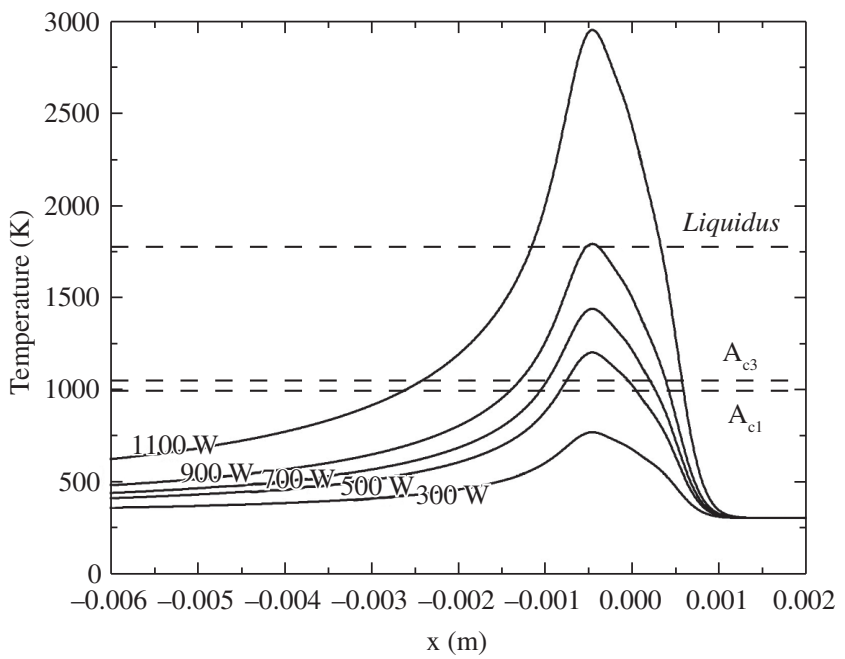

Figure 4. Calculated temperature profile at the surface for each power level as a function of the distance from the laser beam center. Pearlite-to-austenite transformation temperatures (Ac1 and Ac3) and the liquidus are also presented. All temperatures were calculated for a fixed point $50 \mu \mathrm{m}$ below the surface at track centerline and for a laser beam speed of $115 \mathrm{~mm} / \mathrm{s}$.

starting at same point as the previous measurements. The gray bar in Figure $6 \mathrm{~b}$ indicates the intersection (superposition) between consecutive laser tracks, as presented in Figure 3d. Because the overlapping lengths for $\mathrm{P}=900$ and $\mathrm{P}=1100 \mathrm{~W}$ conditions are different, an average width for the gray bar was used.

\section{Discussion}

In terms of microstructure, the longitudinal cross-section metallography revealed two regions: one composed of martensite, called 

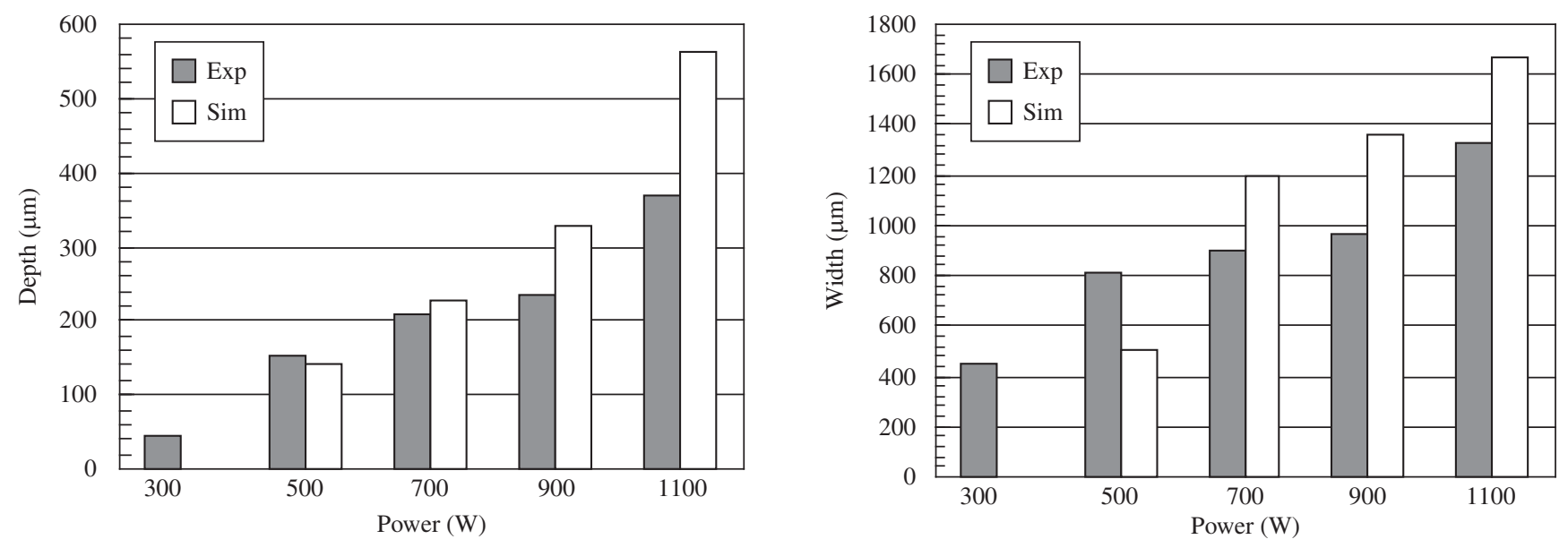

(a)
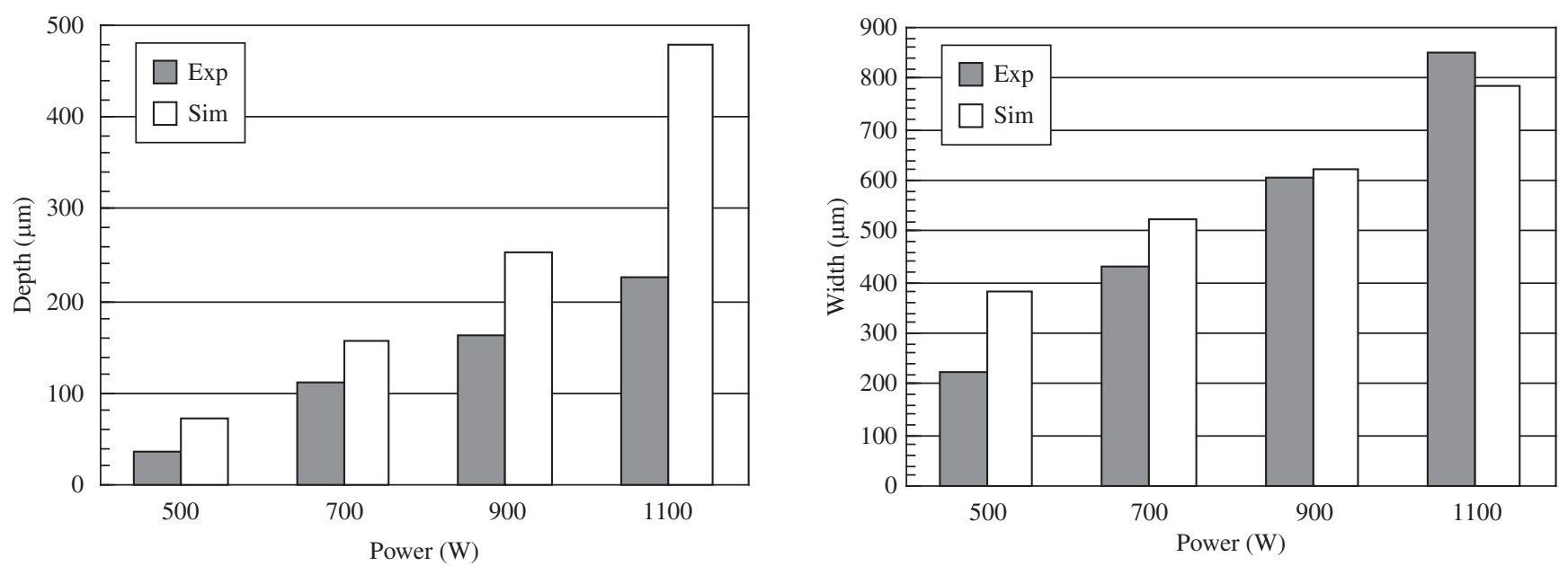

(b)

Figure 5. Comparison between experimental and simulated dimensions of the laser tracks for different power levels. a) Partially transformed region (PTR); and b) martensitic region (MR).

MR, and the other composed of proeutectoid ferrite, unchanged pearlite and martensite, called here the Partially Transformed Region or PTR. Except at $300 \mathrm{~W}$ where the material remained practically unchanged, the rippled shape of the upper surface, indicates that part of the martensite came from melting followed by rapid solidification. Another portion of martensite, between the resolidified layer and the PTR, came from the homogenization of the microstructure, austenitization and rapid cooling. The interface between these two kinds of martensite is not visible and the martensite itself has similar shape and dimensions at the center or the surface of the track. The martensite laths have a typical width of $0.2 \mu \mathrm{m}$ in all analyzed parts of the specimen. The melted layer was very thin if the calculated thermal profile in Figure 5 is correct. From the figure, the melted layer only surpasses $50 \mu \mathrm{m}$ in depth when the laser power is $1100 \mathrm{~W}$.

During heating, the eutectoid structure of pearlite quickly changes to austenite when the temperature rises above Ac1. The rapid diffusion of $\mathrm{C}$ between cementite and ferrite is aided by the small spacing of these phases, only about $0.3 \mu \mathrm{m}$. This means that the interface between the base material and the PTR is quite sharp, as observed, and the reaction does not need overheating. Therefore, the phase transformation from pearlite to austenite begins just above Ac1. On the other hand, the reaction between the austenite and the proeutectoid ferrite at $\mathrm{Ac} 3$ requires long-range diffusion of $\mathrm{C}$ and other elements, as well as a BCC-to-FCC phase change. Here, an overheating of $100 \mathrm{~K}$ was added to the Ac3 reference temperature in order to take this into account. Although the Ac $3+100 \mathrm{~K}$ hypothesis allows a good approximation between the observed and calculated dimensions of the heat-treated regions (Figure 5b), a more strict formulation of the phase change overheating during austenite growth may be necessary to validate the modeling. Under the severe thermal conditions imposed here, solute and kinetics effects on both heating and cooling phase transformations should apply ${ }^{16}$. Consider, for the $900 \mathrm{~W}$ condition, that the beam velocity is $115 \mathrm{~mm} . \mathrm{s}^{-1}$, the heating gradient is $1.7 \times 10^{6} \mathrm{~K} . \mathrm{m}^{-1}$ and the cooling gradient is $2.3 \times 10^{5} \mathrm{~K} . \mathrm{m}^{-1}$ near Ac1 (obtained from the tangents in Figure 4). Looking at the $1100 \mathrm{~W}$ case (Figure 4), the thermal gradients are also high for melting and solidification: $2.4 \times 10^{6}$ and $6.1 \times 10^{5} \mathrm{~K} . \mathrm{m}^{-1}$, respectively. The cooling rate is very high during solidification or Ac1 phase transformation, being approximately $10^{7} \mathrm{~K} . \mathrm{s}^{-1}$ in both cases. These values indicate that the partition coefficients of elements, especially carbon, decrease and the atom attachment kinetics' undercooling or overheating (linked to the ease of removing a single atom from one phase to other) increase. These analyses are beyond the scope of the present work.

Both specific heat and thermal diffusivity (or conductivity) are considered constants for the thermal calculations (Equation 1). These values suddenly modify during phase changes, in particular during 


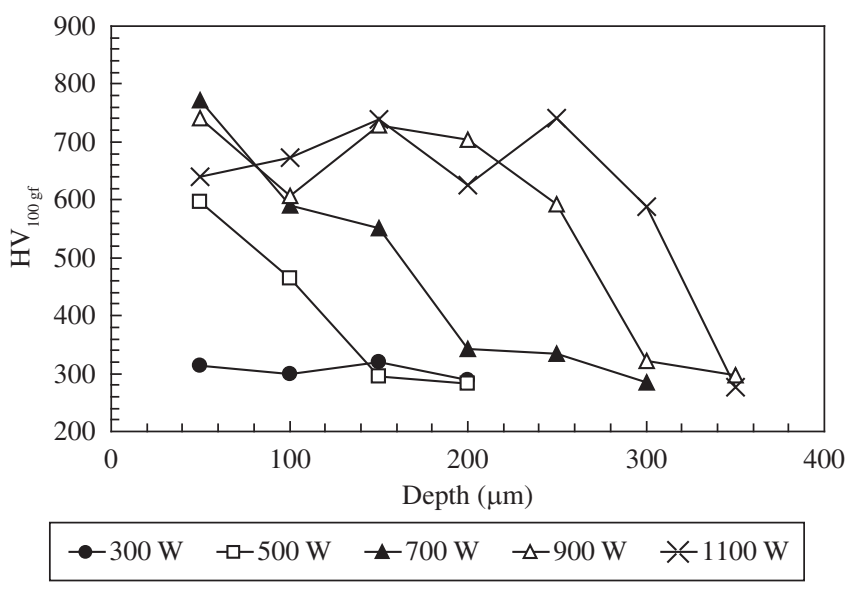

(a)

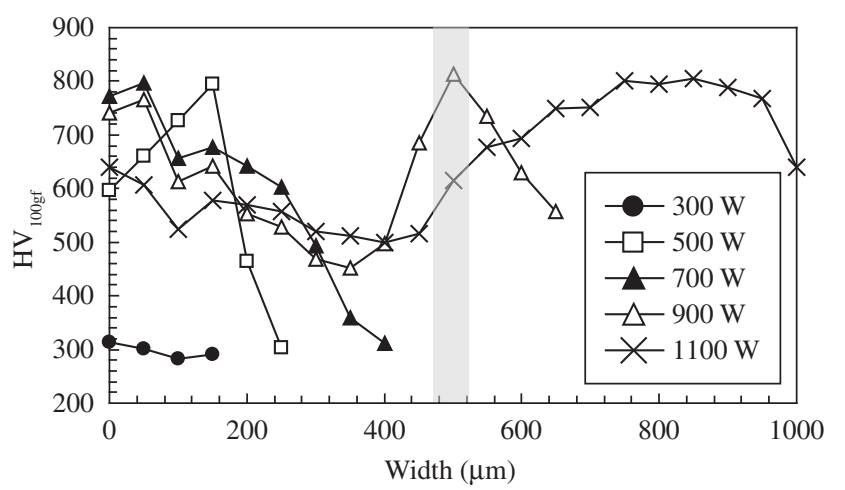

(b)

Figure 6. Microhardness profile for each laser power as a function of a) depth; and b) width. The gray area corresponds to the intersection between consecutive laser tracks.

melting and solidification. However, considering that thermal transfer occurs through conduction inside a massive, cold solid, an average value between ambient temperature and solidus could be considered a good approximation. Another model limitation concerns the latent heat. For example, heat is consumed during melting, and this amount of laser energy will be unavailable for material heating. This may explain why the simulated depths for tracks that experienced melting are higher than the measured depths. As can be seen in Figure 5, the simulation always over-evaluates the depth for the 700, 900 and $1100 \mathrm{~W}$ tracks. More liquid is generated and more disagreement is observed in the data, indicating that some laser energy is used for melting and, when more liquid is generated as by increasing the laser power, the difference increases as well.

Laser absorptivity measurements are also sensitive to melting; however, the results present the percentage of effective laser heating inside the sample. When the energy is sufficient to melt the metal, a drop of $4 \%$ in $\beta$ is observed from 500 to $700 \mathrm{~W}$ (Table 2). Although more energy is coupled to the liquid steel at the surface, because absorptivity in liquid steel is much higher than in the solid, more energy is needed to melt said steel. Some compensation between latent heat losses and increased absorptivity in the liquid occurs from 700 to $900 \mathrm{~W}$ and the $\beta$-value remains unchanged. Further laser power finally allows more heat to dissipate in the form of a temperature rise inside the coupon; the absorptivity reaches nearly $60 \%$ at $1100 \mathrm{~W}$.

The microstructural changes directly affect the hardness of the tracks. The general feature of microhardness profiles inside the heat- treated tracks is a plateau inside the martensitic region $(600-800 \mathrm{HV})$ and then a continuous decrease in HV inside the partially transformed region, which reaches $300 \mathrm{HV}$ at the interface between the PTR and the base material. The observed case depths for each power level are as follows (Figure 6a): $300 \mathrm{~W}$, no hardening effect; $500 \mathrm{~W}, 100 \mu \mathrm{m}$; $700 \mathrm{~W}, 150 \mu \mathrm{m} ; 900 \mathrm{~W}, 250 \mu \mathrm{m}$; and $1100 \mathrm{~W}, 300 \mu \mathrm{m}$.

Now, analyzing the microhardness as a function of width from the laser beam centre (Figure 6b), the HV profiles for $500 \mathrm{~W}$ and $700 \mathrm{~W}$ are as expected, with values between 600 and $800 \mathrm{HV}$ inside the martensitic region and then dropping when far from the laser centerline. However, the behavior is more complicated when partial superposition occurs. In the case of $900 \mathrm{~W}$, the superposition area is as hard as the martensitic region. This comes from the tempering of martensite (Figure 3d,e), which produces a fine dispersion of hard carbide phases. Carbides with an average size of $0.5 \mu \mathrm{m}$ can be seen in Figure 3e. On the other hand, the hardening effect of reheating a previous track is observed far from the intersection zone for the $1100 \mathrm{~W}$ case (Figure 6b, crossed points). The laser power is sufficient to produce tempering in regions embodying half of the previous track volume (Figure 2e), thereby creating a wavy HV pattern.

The best hardening condition depends on the intended use of the final piece and how stresses and wear develop during its lifetime. For the current shaft, the regions of concern are located at each end because the friction and wearing occurs at the fixed ends. A comparative lifetime analysis using both induction and laser-hardened pieces can be used to analyze the overall performance of the shafts. However, this is beyond the scope of the present work.

Here, $\mathrm{N}_{2}$ cooling gas was used because it is cheap, but other gases could be used, including Ar or He. Helium is quite expensive but its heat transfer coefficient is much higher than $\mathrm{N}_{2}$, so the heat extraction could be augmented at the surface. However, heat transfer to the steel volume is principally responsible for the hardening, and so the surface gas could be used only as a protective atmosphere.

Using $\mathrm{N}_{2}$ could lead to some nitridation of the steel surface because nitrogen is easily incorporated into the molten iron. However, this effect is minimized by the short exposure time of the melt to the gas, which is only 16.5 milliseconds if one considers the beam diameter $(1.9 \mathrm{~mm})$ divided by the surface speed $\left(115 \mathrm{~mm} \cdot \mathrm{s}^{-1}\right)$.

The present method could be used to treat an entire shaft as well as specific regions that are especially susceptible to wear. The rotating speed of $120 \mathrm{RPM}$, which is equivalent to $115 \mathrm{~mm} . \mathrm{s}^{-1}$ at the surface, together with the horizontal speed of $2 \mathrm{~mm} \cdot \mathrm{s}^{-1}$, allows treatment of a $14 \mathrm{~cm}$ long shaft within 70 seconds. It is amazing to consider that this is possible for a case depth up to $300 \mu \mathrm{m}$. Larger penetrations are made possible by decreasing the process speed if specific regions have to be treated.

Considering the industrial practice, it is not difficult to turn a shaft on its own axis; this is already done for induction heating. A robot arm could easily position the laser beam and the gas flux at a precise location when the shaft is turning. Convenient robotic programming could change the laser-focusing head in order to follow the surface and maintain the same focusing conditions.

\section{Conclusions}

After the present analyses of the laser-remelted and hardened shaft under different power conditions, the following conclusions could be draw:

- The laser beam heating produces two kinds of regions inside the laser tracks. One region is composed predominately by martensite, called here the MR - Martensitic region. The other region present is unchanged proeutectoid ferrite, martensite and 
some pearlite; it is called the PTR or Partially Transformed Region;

- Temperature evolution during hardening was calculated using Equation 1. However, as the laser-matter absorptivity was an unknown variable, some calorimetric tests were developed. The experimental absorptivity for each laser condition, ranging from 38 to $59 \%$, is presented in Table 2 . The effect of laser power on absorptivity is driven by two variables: the increase in laser absorptivity when more liquid is produced with increasing power, and the decrease in the total heat available due to the steel's latent heat of fusion;

- These effects are also seen when one compares the experimental and simulated dimensions of the transformed regions (MR and PTR) (Figure 5). The thermal model shows overall good agreement with the experimental results, but the measured depths for the MR and PTR are always larger than the simulated results. It is assumed that some heat is lost during melting, which is not considering in the model. Another factor to be considered is the value of the $100 \%$ austenitic transformation temperature $(\mathrm{Ac} 3+100 \mathrm{~K})$, which is constant in the present analysis, however it is expected to vary in response to different cooling rates;

- The case depth varies with the laser power. The maximum hardened depth is $0.3 \mathrm{~mm}$ for a laser power of $1100 \mathrm{~W}$. Under high power, 900 and $1100 \mathrm{~W}$, the laser tracks partially overlap; therefore, some tempering occurs at the overlapped zones; and

- The current methodology shows a promising alternative to induction-hardened shafts and could be easily implemented within the production process. The method is rapid and allows treatment of specific surfaces on the piece.

\section{Acknowledgments}

This work was funded by the Institute Factory of Millennium (IFM/CNPq-MCT/Brazil) and FINEP (Financiadora de Estudos e Projetos)/Brazil. The authors would like to thank the LME/LNLS for technical support during electron microscopy work.

\section{References}

1. Bach J, Damascheck R, Geissler E, Bergmann HW. Laser transformation hardening of different steels. In: Bergmann HW and Kupfer R, editors.
Proceedings of the $3^{\mathrm{rd}}$ European Conference on Laser Treatment of Materials (ECLAT'90); 1990 Sep 17-19; Coburg, Germany: Sprechsaal Publising Group.; 1990. p. 265-282.

2. Hino M, Hiramatsu M, Akiyama K, Kawasaki H, Tsujikawa M, Kawamoto M. Surface Hardening of Carbon Steel Using High Powered YAG Laser. Mater. Manufacturing Proc. 1997; 12(1):37-46.

3. Peng RL, Ericsson T. Residual stress distributions in laser transformation hardened steels. Scand. J. Metallurgy. 1998; 27(5):223-232.

4. Chiang KA, Chen YC. Laser surface hardening of H13 steel in the melt case. Mater. Letters. 2005; 59(14-15):1919-1923.

5. Selvan JS, Subramanian K, Nath AK. Effect of laser surface hardening on En18 (AISI 5135) steel. J. Mater. Proc. Technol. 1999; 91(1-3):29-36.

6. Lo KH, Cheng FT, Man HC. Laser transformation hardening of AISI 440C martensitic stainless steel for higher cavitation erosion resistance. Surf. Coat. Technol. 2003; 173(1):96-104.

7. Obergfell K, Schulze V, Voehringer O. Classification of microstructural changes in laser hardened steel surfaces. Mater. Sci. Engineering A. 2003; 355(1-2):348-356.

8. Kennedy E, Byrne G, Collins DN. A review of the use of high power diode lasers in surface hardening. J. Mater. Proc. Technol. 2004; 155-156:1855-1860

9. Hunziker O. Cartes de microstructure de solidification dans le système Ni-Ni3Al-NiAl. [PhD. Thesis no. 1687]. Switzerland: Ecole Polytechnique Fédérale de Lausanne, EPFL; 1997.

10. Rosenthal D. The Theory of Moving Source of Heat and it's Application to Metal Treatment. Transactions A.S.M.E. 1946; November: 849-866.

11. Callister Jr. WD. Materials Science and Engineering: An Introduction, Sixth Edition: London: John Wiley \& Sons, Inc; 2003.

12. ThermoCalc thermodynamic database, version J, Stockholm Royal Institute, Sweden; 1994.

13. Ion JC. Laser Processing of Engineering Materials, Oxford: Elsevier; 2005. p. 556

14. Frenk A, Hoadley AFA, Wagniere JD. In-situ technique for measuring the absorption during laser suface remelting. Metall. Trans. B. 1989; 22(1):139-142.

15. Lima MSF, Wagniere JD, Determinação da absorção do feixe laser em ensaios de refusão em regime contínuo. Revista de Metalurgia. 1998; 32(2):131-134

16. Kurz W, Fisher DJ. Fundamentals of Solidification, 4 edition, Lausanne (Switzerland): Trans Tech Publications; 1992. 